\section{O Editor Presta Contas (parte 3): Um Retrospecto do Desempenho Financeiro dos "Arquivos" nos Últimos Anos}

$\mathrm{C}$ om este editorial, finalizo a série "O Editor Presta Contas" justamente na edição de Agosto, há poucas semanas da realização do $25^{\circ}$. Congresso Brasileiro de Endocrinologia e Metabologia, em Brasília, onde será discutida pelo Conselho Deliberativo da SBEM a renovação da direção da revista para o próximo período. Este material serve, assim, para justificar a necessária prestação de contas não somente com aquele Conselho, mas também com todos os seus sócios e leitores da revista.

\section{O ORÇAMENTO DOS ABE\&M}

A receita anual dos Arquivos é composta essencialmente de 3 fontes: 1comercialização de anúncios veiculados nas páginas da revista (em especial da indústria farmacêutica); 2 - parcela da anuidade dos sócios repassada pela Diretoria Nacional da SBEM e; 3- auxílio editoração para revistas científicas, obtido junto a instituições governamentais.

Já o custo da publicação da revista é composto das seguintes parcelas principais: 1- processo de digitação, diagramação, composição e revisões (despesas de pré-impressão); 2 - fotolitos, papel, montagem e acabamento (impressão) e; 3- manuseio e distribuição (pós-impressão).

Nos últimos anos, o orçamento global dos ABE\&M tem se mantido razoavelmente equilibrado. A receita, contudo, varia sazonalmente e está aquém do desejável, pois o preço dos anúncios dificilmente acompanha a inflação, visto que: 1- a qualquer ameaça de depreciação da moeda, a indústria prontamente declina de permanecer anunciando, 2- a contribuição associativa, quando quitada, apenas acompanha o salário mínimo (SM), e 3- o auxílio editoração é ocasional, dependendo de esforços pessoais do editor e das condições financeiras momentâneas das instituições de apoio. Por outro lado, as despesas para publicação sofrem elevações constantes, acompanhando ou suplantando as taxas de inflação e, muitas vezes, as disparadas inconvenientes do dollar. Desta maneira, parece mais sensato aumentar o número de anunciantes do que o valor do anúncio propriamente dito. Temo, entretanto, que a dependência exagerada dos anunciantes seja problemática, sendo preferível alicerçarmo-nos em bases mais sólidas como a contribuição efetiva dos associados e assinantes. Como procuramos melhorar a qualidade da impressão, do papel e do processo de revisão, além do aumento absoluto da tiragem, do número de artigos e de páginas impressas, é evidente que temos que pesar a cada momento os recursos possíveis contra um programa de publicação regular a médio e longo prazo.

A publicação dos Arquivos passou a ser administrada diretamente pelos editores à partir de 1993, ainda na gestão de Rui Maciel, tendo ele, Antonio Carlos Bianco e eu próprio assumido esta responsabilidade, dada a relativa falta de autonomia financeira e dificuldades de controle junto à empresa que editava a revista até então.

\section{editorial}

Claudio E. Kater
Disciplina de Endocrinologia,
Departamento de Medicina,
UNIFESP/EPM
Editor-chefe, ABEEM 
Embora editores anteriores também tivessem se empenhado na obtenção de recursos para financiar a revista, até aquele momento jamais esta responsabilidade adicional havia sido incorporada às atribuições meramente científicas do editor.

Pela inexperiência, os primeiros anos foram intranqüilos, quando o orçamento era mais restrito e as dificuldades maiores. Apesar disto, pouco depois fizemos importantes realizações. Quando a revista passou a se auto-sustentar e o orçamento tornou-se equilibrado, foi possível aumentar a tiragem, a periodicidade, a quantidade de artigos e páginas, e a qualidade de impressão e do material publicado. Conseguiu-se, da mesma maneira, maior rapidez e eficiência na distribuição da revista, apesar do aumento constante dos custos, tanto de impressão como de distribuição. O quadro 1. apresenta um demonstrativo financeiro dos ABE\&M nos últimos 4 anos, quando a revista tornou-se bimestral.

Apesar de compromissada, a parcela da receita relativa à comercialização de anúncios é hoje substancial e indispensável, permitindo ajustes dentro dos parâmetros econômicos de mercado. Já a contribuição relativa ao repasse de anuidades é frequentemente inconstante, além de atrelada ao SM, o índice econômico mais desatualizado que se pode utilizar. Da mesma forma, a terceira parcela - o auxílio de instituições de fomento -, dependem exclusivamente do interesse e aplicação do editor junto a elas e, claro, do desempenho da revista e da disponibilidade financeira da própria instituição, apêndices de Ministérios do Governo com progressivo engessamento orçamentário. Com frequência, o auxílio solicitado apenas é liberado, quando outorgado (e com os cortes previstos), nos últimos dias do ano subsequente, devendo-se contabilizar as perdas consequentes à desvalorização da moeda. Nos últimos 3 anos fomos contemplados com um auxílio anual de R\$22.500,00, menos da metade do que fora solicitado.

A parcela de contribuição dos sócios é um problema constante: primeiro, porque apenas 60\% (média dos últimos 4 anos) de todos os associados inscritos $\mathrm{e}$ cadastrados paga sua quase simbólica contribuição anual com regularidade; segundo, porque não é habitual que as diretorias regionais da SBEM repassem suas parcelas (50\% da anuidade) pontualmente para a Diretoria Nacional e esta, consequentemente, aos ABE\&M $(20 \%)$. Razões variadas (inadimplência da regional, "perdão" da Nacional, valores defasados ou com descontos) fazem com que o valor final repassado aos ABE\&M seja de apenas 80 a $90 \%$ da receita, mesmo

Quadro 1. Demonstrativo financeiro dos "Arquivos" nos últimos 4 anos, quando a revista passou a circular bimestralmente.

\begin{tabular}{|c|c|c|c|c|c|c|c|c|}
\hline ANO & \multicolumn{2}{|c|}{1998} & \multicolumn{2}{|c|}{1999} & \multicolumn{2}{|r|}{2000} & \multicolumn{2}{|r|}{2001} \\
\hline Edições Regulares/Suplementos & 6 & 1 & 6 & 4 & 6 & 2 & 6 & 6 \\
\hline Tiragem média/edição & 2500 & 3000 & 2583 & 1475 & 2500 & 3100 & 3200 & 2017 \\
\hline Total de páginas/edição & 98 & 352 & 106 & 145 & 117 & 204 & 128 & 164 \\
\hline Páginas texto/edição & 87 & 335 & 88 & 138 & 96 & 186 & 115 & 155 \\
\hline Páginas anúncios/edição & 14 & 20 & 22 & 11 & 24 & 22 & 16 & 13 \\
\hline Custo Médio do Anúncio: R\$ & 1666.03 & 1576.00 & 1604.90 & 1230.95 & 1547.17 & 1575.86 & 1852.94 & 1989.17 \\
\hline US\$ & 1426.16 & 1321.15 & 868.75 & 682.42 & 841.42 & 823.86 & 791.18 & 801.85 \\
\hline Valor US\$ em R\$ & 1.17 & 1.19 & 1.85 & 1.81 & 1.84 & 1.91 & 2.36 & 2.50 \\
\hline \multicolumn{9}{|l|}{ RECEITA } \\
\hline Receita Bruta: R\$ & 23880.00 & 31520.00 & 34470.00 & 12957.50 & 36935.17 & 33893.00 & 29928.83 & 24186.83 \\
\hline US\$ & 20433.34 & 26423.00 & 18609.36 & 7230.17 & 20167.57 & 17677.36 & 12726.85 & 9707.45 \\
\hline Receita Líquida: R\$ & 19104.00 & 25216.00 & 27576.00 & 10366.00 & 29548.13 & 27114.40 & 23943.07 & 19349.47 \\
\hline US\$ & 16346.67 & 21138.40 & 14887.49 & 5784.14 & 16134.05 & 14141.89 & 10181.48 & 7765.96 \\
\hline \multicolumn{9}{|l|}{ DESPESAS } \\
\hline Composição/Filmes/Fotos: RS & 3575.00 & 3300.00 & 3575.00 & 3637.50 & 3454.53 & 3955.17 & 3203.82 & 4114.13 \\
\hline US\$ & 3060.00 & 2766.37 & 1928.04 & 2011.56 & 1876.33 & 2065.74 & 1355.39 & 1645.43 \\
\hline Editoração/Revisão/Correção: RȘ & 2600.00 & 3350.00 & 2625.00 & 2025.00 & 2890.00 & 1855.00 & 3435.00 & 2138.33 \\
\hline US\$ & 2225.46 & 2808.28 & 1415.69 & 1119.84 & 1569.70 & 968.85 & 1453.19 & 855.22 \\
\hline Papel/Impressão Gráfica: R\$ & 13038.33 & 9700.00 & 12314.17 & 10635.00 & 12080.00 & 16195.00 & 14778.33 & 12056.67 \\
\hline US\$ & 11160.09 & 8131.44 & 6641.17 & 5881.21 & 6561.24 & 8458.46 & 6252.03 & 4822.02 \\
\hline Distribuição/Postagem: R\$ & 1856.49 & 500.00 & 2095.56 & 1375.00 & 2735.95 & 1406.80 & 3187.80 & 1083.33 \\
\hline US\$ & 1589.05 & 419.15 & 1130.16 & 760.38 & 1486.03 & 734.75 & 1348.61 & 433.28 \\
\hline TOTAL DE DESPESAS: RS & 21069.82 & 16850.00 & 20609.73 & 17672.50 & 21160.48 & 23411.97 & 24604.95 & 19392.47 \\
\hline US\$ & 18034.60 & 14125.24 & 11115.06 & 9772.99 & 11493.29 & 12227.81 & 10409.21 & 7755.95 \\
\hline Custo Unitário do exemplar: R\$ & 8.43 & 5.62 & 7.98 & 11.98 & 8.46 & 7.55 & 7.69 & 9.62 \\
\hline US\$ & 7.21 & 4.71 & 4.30 & 6.63 & 4.60 & 3.94 & 3.25 & 3.85 \\
\hline Superávit/ Déficit verificado: R\$ & -1965.82 & 8366.00 & 6966.27 & -7306.50 & 8387.65 & 3702.43 & -661.88 & -43.00 \\
\hline US\$ & -1682.64 & 7013.16 & 3756.99 & -4040.54 & 4555.74 & 1933.74 & -280.01 & -17.20 \\
\hline Superávit/ Déficit no período: R\$ & -11794.94 & 8366.00 & 41797.64 & -29226.00 & 50325.90 & 7404.87 & -3971.30 & -258.01 \\
\hline US\$ & -10095.81 & 7013.16 & 22541.94 & -16162.14 & 27334.44 & 3867.48 & -1680.07 & -103.19 \\
\hline
\end{tabular}


contando-se somente com os sócios pagantes (perfazendo, portanto, $50 \%$ do total previsto). Apenas para ilustrar o quão atenuada tem se tornado a cota da contribuição associativa para a manutenção da revista, imaginemos que "todos" os sócios cadastrados tivessem pago sua anuidade em 2002; a revista deveria ter recebido R\$ 90.000,00 (20\% do total de 2.500 sócios pagando I SM vigente - R\$ 180,00). Este recurso cobriria, apertado, o custo de apenas 3 edições no padrão atual. Não temos ainda o valor a ser repassado em 2002 mas em 2001, a revista recebeu $\mathrm{R} \$ 45.000,00$ !

Este assunto costuma ser debatido entre a direção da revista e a Diretoria da SBEM (melhor seria, da coordenadoria da FEBRASEM, englobando as demais sociedades) mas ambas se mostram relativamente impotentes frente ao costumeiro desinteresse de boa parcela dos associados. É importante que este grupo percebesse o quanto seu eventual atraso ou esquecimento pode ser prejudicial para o bom funcionamento dos ABE\&M e, claro, de toda a Sociedade.

Nesta linha, há um outro número que os leitores precisam conhecer melhor: quanto custa a revista para seus bolsos. Como o repasse da contribuição anual é sempre o mesmo desde há décadas ( $20 \%$ do SM, ou seja R\$ 36,00/ano) um exemplar dos ABE\&M custa hoje para eles R\$ 6,00, tanto quanto Veja, Época ou Isto É e muito menos do que Casa \& Jardim, Gula ou Playboy. O custo do exemplar, contudo, está hoje na faixa de $\mathrm{R} \$ 9,00$ a 10,00. Em contrapartida, hoje em dia eles recebem pontualmente 6 exemplares anuais (fora eventuais suplementos) de uma revista de ótima qualidade, com conteúdo científico de primeira, tanto em quantidade como em qualidade, permitindo seu aprimoramento e capacitação profissionais constantes. Não temos ainda condição de distribuir a todos os associados os 4 a 6 suplementos anuais da revista, contendo a programação científica e os resumos de trabalhos dos congressos patrocinados pela FEBRASEM. Mas, é conveniente que saibam que todos os congressistas recebem, desde há alguns anos, uma revista indexada contendo este material, sem qualquer custo para os organizadores do evento, embora sejam dispendiosos. Portanto, com a mesma receita levantada, estamos publicando na verdade 10 a 12 edições anuais dos ABE\&M.

É oportuno mencionar que boa parte dos recursos obtidos das instituições de financiamento de publicações científicas e eventuais superavits da venda de anúncios têm sido empregados em programas de implementação da revista virtual e formatação especial para colocação na rede SciELO, ou alocados para projetos especiais como a confecção de números especiais (50 anos da SBEM; Cinqüentenário do ABE\&M) etc.

\section{A MANUTENÇÃO DA SEDE DOS ARQUIVOS}

Desde há 5 anos, parte da receita da Diretoria Nacional da SBEM cobre também outra despesa indireta dos Arquivos: a manutenção de sua sede e escritório. É indiscutível que a aquisição desta sede durante a gestão presidida por Luiz de Lacerda Filho, e o compromisso de sua manutenção pelas Diretorias subsequentes da SBEM, possibilitou enorme crescimento e desenvolvimento organizacional da revista. $\mathrm{O}$ escritório editorial dos Arquivos é apenas uma sala comercial de $39 \mathrm{~m} 2$, na qual todos os manuscritos, documentos, arquivos e sobras de revistas são mantidos. Seu patrimônio (parte pertencente à Diretoria Regional da SBEM-São Paulo) é composto de 3 linhas telefônicas com 3 aparelhos, 1 fax, 3 computadores, 2 impressoras, 1 scanner, 1 fotocopiadora, 1 máquina de escrever, vários softwares e mobiliário típico de escritório. As despesas, da ordem de R\$2.500,00 mensais, cobrem $50 \%$ do salário de um secretária, de uma auxiliar de limpeza, das despesas fixas de condomínio, de energia elétrica, telefone, internet e correio (para correspondências de rotina), compra de material de escritório e gastos eventuais de manutenção de equipamento. A outra metade da despesa é coberta pela Diretoria da Regional de São Paulo da SBEM, que divide a sala com os ABE\&M.

A regularidade dos Arquivos e seu crescimento dependem da manutenção desta estrutura mínima de funcionamento. A preocupação, o compromisso e o empenho das várias Diretorias Nacionais da SBEM, com o sucesso desta empreitada merecem a gratidão e o reconhecimento de todos nós.

\section{ENDOCRINOLOGA MOLECULAR}

Desde a era das quantificações hormonais indiretas, por aferição de peso e medidas teciduais (endocrinologia "pré-histórica"), passando pelos ensaios bioquímicos elementares (quando hormônios só podiam ser dosados se na faixa de concentração de $\mathrm{mg} / \mathrm{dl}$ ) e os radio-, imuno-, fluoro-, enzimo-, etc-ensaios, através dos quais quantidades da ordem de ng ou $\mathrm{pg} / \mathrm{ml}$ podem ser fácil e prontamente aferidas, até o século 21 , onde a biologia/genética molecular se firmou como um novo marco no processo de desenvolvimento da medicina, permitindo a identificação de alterações genéticas mínimas, a endocrinologia tornou-se adulta. Um pouco diferente de décadas atrás, quando na maioria das vezes estávamos, nós brasileiros, sempre um pouco a reboque das façanhas da ciência norte- 
americana e européia, na era da genômica tornamonos, por razões que desconheço, muito mais competitivos. Estamos, em mais de uma área de atuação, provavelmente na mesma linha de fronteira dos "concorrentes" internacionais, para não dizer à sua frente, algumas vezes. Neste número dos ABE\&M, que poderia ter sido publicado como um "Pequeno Tratado de Biologia Molecular em Endocrinologia", muitos dos conhecidos colegas e, felizmente, outros tantos ainda desconhecidos (já que jovens e emergindo), falam com conhecimento de causa sobre um assunto novo e fascinante, e que ainda há pouco assustava. Da pesquisa essencialmente básica e sem aplicações imediatas para o mortal endocrinologista de consultório, aqui já são delineadas aplicações da $\mathrm{BM}$ em diagnóstico e tratamento de condições comuns da endocrinologia clínica.

Ana Claudia Latronico - de Santos para a USP, de lá para Bethesda, de volta para a USP e agora para o mundo -, montou um temário e agregou um conjunto de pessoas que conseguem escrever com propriedade e experiência sobre seu tema, transmitindo conhecimento novo e moderno ao leitor da revista. Eu mesmo um "late bloomer" nesta nova arte, pude apreciar - com certa resignação por não ter tido a sorte de ter nascido uma década depois (mas então teria perdido toda aquela fascinante loucura dos anos 60!) -, toda a beleza secreta que existe na intimidade dos mecanismos endócrinos. Deveria estar acostumado, após estes anos todos à frente da editoria da revista, com a progressão geométrica do conhecimento científico na nossa área, desenvolvido pelos colegas brasileiros. Mas ainda me surpreendo quando folheio atentamente este rico material. Sentindo-me humildemente orgulhoso por estar de alguma maneira envolvido neste processo, tenho o prazer de cumprimentar a todos os autores pela produção desta obra robusta e atual. Obrigado, em especial, à Ana Claudia, uma mulher plural, sem deixar de ser singular: amiga e confidente, incansavelmente profícua e competente, objetiva e focalizada, consegue também harmonizar sua vida de esposa e mãe.

\section{OS PRÊMIOS ABE\&M - 2001}

Para manter o sigilo e uma certa surpresa às vésperas do $25^{\circ}$. Congresso Brasileiro de Endocrinologia e Metabologia, os Prêmios ABE\&M - 2001: Professor Waldemar Berardinelli (para o melhor trabalho publicado na área de Endocrinologia Clínica) e Professor Thales Martins (seu correspondente na área de Endocrinologia Básica), somente estão sendo divulgados nesta edição de Agosto de 2002. Sua entrega (cer- tificado, placa e cheque no valor de $\mathrm{R} \$ 2.500,00)$ acontecerá em solenidade oficial durante o encerramento do referido congresso, no dia 24 de setembro próximo. Foram convidados para compor a Comissão Julgadora destes Prêmios, membros do Conselho Editorial da revista, todos brasileiros residindo atualmente no exterior. Fiz esta opção, na tentativa de, não abrindo mão da qualidade do julgamento, minimizar possíveis interferências pessoais e tendenciosidades inevitáveis; foram eles (por ordem alfabética de primeiro nome): Antonio Carlos Bianco, Décio Eizirik, Gilberto Velho, Helena W. Rodbard, Julio Licinio e Patrícia Dahia, permitindo-me o direito de eventual - mas felizmente desnecessário, - voto de minerva. Agradeço a todos eles pelo interesse e atenção, mesmo que nem todos tivessem podido participar deste primeiro julgamento. Os votos computados, entretanto, foram suficientes para estabelecer um consenso. Reforco que, conforme previamente estabelecido, somente foram considerados nesta avaliação os trabalhos originais tendo-se excluído revisões, atualizações, casuísticas, apresentações de casos e editoriais. Vamos aos vencedores:

1) O Prêmio ABE\&M - Professor Waldemar Berardinelli, oferecido para o melhor trabalho publicado nos Arquivos Brasileiros de Endocrinologia e Metabologia durante o ano de 2001 na área de Endocrinologia Clínica, está sendo concedido ao autor principal do artigo: Terapia de Reposição Hormonal Contínua na Pós-Menopausa: Ênfase no Hormônio de Crescimento, Insulina, Fator de Crescimento Semelhante à Insulina I (IGF-I) e Proteína Ligadora 3 do IGF (IGFBP3). Denise Ginzbarg, Rosimeire J. Teixeira, Trude Dimetz, Jodélia L.M. Henriques \& Hildoberto C. Oliveira (Arq Bras Endocrinol Metab 2001;45/4:390-400).

2) O Prêmio ABE\&M - Professor Thales Martins, concebido para o melhor trabalho publicado nos Arquivos Brasileiros de Endocrinologia e Metabologia durante o ano de 2001 na área de Endocrinologia Básica, está sendo concedido ao autor principal do artigo: Efeitos da Dietilpropiona, Energia da Dieta e Sexo Sobre o Ganho de Peso Corporal, Peso dos Órgãos e Deposição de Tecidos em Ratos. Leticia H. Bellaver, Maria A. Vital, Ana Maria Arruda \& Claudio Bellaver (Arq Bras Endocrinol Metab 2001;45/2:167-172)

A ambas as vencedoras (para reconfirmar a estatística de que as mulheres estão cada vez mais "visíveis" na nossa sociedade), às suas mentoras $\mathrm{e}$ colaboradoras (novamente mais elas dos que eles!), os nossos cumprimentos e votos de contínuo brilhantismo na carreira. 